\title{
Comentário
}

\section{Psicanálise, universidade e pesquisa: relacionamento possível}

Freud ${ }^{1-5}$ pioneiro e êmulo do diálogo entre a psicanálise e a universidade, simultaneamente, valorizou e questionou a aproximação entre uma e outra, reconhecendo a importância da utilização do conhecimento psicanalítico na formação de profissionais de saúde e do saber das ciências humanas, atribuindo, no entanto, às instituições autônomas a tarefa especializada de formação dos psicanalistas. Mesmo sofrendo resistências, no meio universitário, às suas descobertas, Freud não deixou de tentar manter um relacionamento com a academia, tendo sido livre-docente e professor assistente da Universidade de Viena, onde procurou divulgar as idéias psicanalíticas através de conferências durante trinta anos.

Ferenczi, no entanto, foi o primeiro a conquistar uma cátedra de psicanálise na universidade, motivando Freud a escrever o artigo no qual se dedica a explicitar suas idéias sobre a possibilidade do ensino da psicanálise na universidade. Freud ${ }^{3}$ propôs o ensino da psicanálise nas escolas médicas em dois níveis: um curso elementar para os estudantes de medicina e um curso especializado para os médicos psiquiatras. Nas escolas das ciências humanas propôs a inclusão do ensino do método psicanalítico, visando a contribuir para a criação de uma união mais estreita entre a ciência médica e os ramos do saber que correspondem ao âmbito da filosofia. A docência de psicanálise na universidade seria exercida predominantemente através de aulas teórico-expositivas e, em casos especiais, poderiam ser realizados experimentos ou demonstração prática. Com relação à prática de pesquisa, recomendava, principalmente, que existissem consultórios para prover o material clínico de pacientes com transtorno neurótico.

As resistências sofridas por Freud, no espaço universitário, após persistentes tentativas de dialogar com seus pares na academia, decepcionaram-no, o que refletiu na sua proposta de formação dos psicanalistas e no modo como empreendeu o desenvolvimento da ciência psicanalítica. O conhecimento psicanalítico prescindia da universidade para o seu desenvolvimento, já que o terreno para as suas investigações era a relação bipessoal. A reflexão sobre suas descobertas, que poderia ter sido enriquecida, desde o início, por meio do diálogo com seus pares na academia, caso a universidade não tivesse adiado a sua participação, ocasionou um grande hiato no diálogo da psicanálise com a universidade, desde Ferenczi até os autores e pesquisadores contemporâneos, como Laplanche, Fedida, Wallerstein, Kernberg e Fonagy.

Laplanche, ${ }^{6,7}$ ratificando o posicionamento freudiano, considera que um ensino digno de tal nome nas ciências humanas não pode ser outra coisa senão o correlativo de uma pesquisa. Do problema da oposição entre o "saber" e a "verdade" subsiste o fato de que não pode haver surgimento da verdade sem a base inicial de um certo saber. Requerer uma exclusividade desse ensino para os que trazem uma bagagem de análise pessoal revela, antes de mais nada, uma descrença na receptividade do inconsciente à psicanálise, uma vez que ela se prolonga em auto-análise e, mais ainda, é precedida por uma auto-análise. A psicanálise deve tirar todo o proveito que puder da relação de forças entre os saberes presentes na universidade para que esteja aberta a todas as correntes.

É com base nessas reflexões teóricas que desenvolvo, no Instituto de Psiquiatria da Universidade Federal do Rio de Janeiro (IPUB), o projeto de pesquisa Contribuição do saber psicanalítico ao campo da Psiquiatria e da Saúde Mental: pesquisa interdisciplinar. ${ }^{8}$ Esse projeto abre um leque de possibilidades para investigar o sofrimento humano a partir da interface do saber psicanalítico com o campo da psiquiatria e o da saúde mental, buscando cumprir o compromisso de produção e de transmissão de conhecimento e de formação profissional no âmbito da universidade. Considerando-se que o Programa de Pós-Graduação em Psiquiatria, Psicanálise e Saúde Mental do IPUB está organizado, na etapa atual, em quatro linhas de pesquisas (as pesquisas oriundas do saber psicanalítico foram incluídas no escopo da linha intitulada Diagnóstico e Tratamento em Psiquiatria), o projeto se interessa tanto pela questão do diagnóstico como pela do tratamento, numa perspectiva interdisciplinar, mantendo, assim, a identidade necessária dos saberes da psicanálise e da psiquiatria.

Essa pesquisa pretende ser uma contribuição, com espírito crítico, levando em conta as contribuições científicas internacionais mas compromissada com a realidade brasileira. Nessa perspectiva, busca-se desenvolver uma análise crítica dos sistemas classificatórios contemporâneos dos transtornos mentais e seleciona, particularmente, o Transtorno de Personalidade Narcisista, considerado condição ainda como critério provisório para ser admitido como diagnóstico pela Organização Mundial da Saúde (OMS) na $10^{\mathrm{a}}$ edição da Classificação Internacional de Doenças (CID-10). ${ }^{9}$ Justifica-se a seleção do Transtorno de Personalidade Narcisista pelo fato de a OMS, no livro intitulado Critérios diagnósticos para pesquisa $C I D-10,{ }^{10}$ estimular pesquisas que busquem oferecer subsídios para clarificar a natureza e o status desse transtorno.

No âmbito da terapêutica, cujo referencial é a Teoria Psicanalítica, focalizam-se as práticas psicoterapêuticas, particularmente a Psicoterapia Psicanalítica Breve ou de Tempo Delimitado, ${ }^{11}$ buscando, desse modo, oferecer subsídios ao Comitê Técnico Científico de Saúde Mental do Ministério da Saúde para a implementação da resolução $\mathrm{n}^{\circ} 11$, de 3 de novembro de 1998, que trata da inclusão de cobertura de assistência em saúde mental pelas seguradoras e planos de saúde.

Theodor S. Lowenkron

Faculdade de Medicina da UFRJ Sociedade Brasileira de Psicanálise do Rio de Janeiro 


\section{Referências}

1. Freud S. Cinco conferencias sobre psicoanálisis (1910). In: Etcheverry JL, trad. Obras Completas. Buenos Aires: Amarrortu; 1990. v. 11.

2. Freud S. Conferencias de introducción al psicoanálisis (1916-1917). In: Etcheverry JL, trad. Obras Completas. Buenos Aires: Amarrortu; 1990. v. 15 e 16.

3. Freud S. Debe enseñarse el psicoanálisis en la universidad? (1919). In: Etcheverry JL, trad. Obras Completas. Buenos Aires: Amarrortu; 1990. v. 17.

4. Freud S. Presentación autobiográfica (1925). In: Etcheverry JL, trad. Obras Completas. Buenos Aires: Amarrortu; 1990. v. 20.

5. Freud S. Nuevas conferencias de introducción al psicoanálisis (1933). In: Etcheverry JL, trad. Obras Completas. Buenos Aires: Amarrortu; 1990. v. 22.

6. Laplanche J. Probemáticas I: a angústia. In: Álvaro Cabral, trad. São Paulo: Martins Fontes; 1987.
7. Laplanche J. Probemáticas IV: o inconsciente e o id. In: Álvaro Cabral, trad. São Paulo: Martins Fontes; 1992.

8. Lowenkron TS. Contribuição do saber psicanalítico ao campo da Psiquiatria e da Saúde Mental: pesquisa interdisciplinar. [Projeto de Pesquisa registrado na UFRJ/SIGMA (Sistema Integrado de Gerenciamento Acadêmico), Código No. 4195]; 1998.

9. Organização Mundial da Saúde. CID-10 (Classificação Estatística Internacional de Doenças e Problemas Relacionados à Saúde). 6a edição, $10^{\mathrm{a}}$ revisão. São Paulo: Edusp; 1998.

10. Organização Mundial da Saúde. CID-10 Critérios diagnósticos para pesquisa (Classificação de Transtornos Mentais e de Comportamento da CID-10). Porto Alegre: Artes Médicas; 1998.

11. Lowenkron TS. Psicoterapia psicanalítica breve. Porto Alegre: Artes Médicas Sul; 1993. 